\title{
Accelerated Reader and Information Policy, Information Literacy, and Knowledge Management: U.S. and International Implications
}

\author{
Nancy EVERHART \\ Associate Professor, \\ Eliza T. DRESANG \\ Eliza Atkins Gleason Professor, \\ Bowie KOTRLA \\ Associate in and Director of Information \\ College of Information, Florida State University, USA
}

\begin{abstract}
Qualitative and quantitative analyses of the relationship between the Accelerated Reader $(A R)$, a computerized reading management program, and information policy, information literacy, and knowledge management are drawn from data collected in the U.S., Scotland, and England. A study of 632 of the poorest U.S. schools shows a strong relationship between national information policy regarding achievement in the No Child Left Behind Act of 2001 and local decisions to use AR, expectations for literacy, and library collection development. Investigation in the U.K. schools finds that (a) motivational style interacts with gender in relation to the competitive and social aspects of the AR program, (b) the level of program implementation does not correlate with breadth of reading, and (c) management aspects of the program are not utilized effectively. Results suggest that how the AR program relates to information policy, information literacy, and knowledge management has importance for school librarians and libraries
\end{abstract}

\section{Introduction}

This research sheds light on the relationships between the Accelerated Reader (AR) program, and information policy, information literacy, and knowledge management through analysis of data collected from applications to a private foundation in the United States (U.S.) that gives annual grants of $\$ 5,000$ for books to the poorest school libraries ${ }^{1}$ and from case studies in Scotland and England. The U.S. data present the point of view of adults involved in school library collection development; the United Kingdom (U.K.) data reveal the point of view of students in the AR program. Collectively, the data allow for a cross-cultural, multi-perspective analysis that informs current understanding and future research.

\section{Accelerated Reader}

The Accelerated Reader (AR) is a computerized reading management program, introduced in the U.S. in 1986 that assesses the reading level of students, quizzes them on their comprehension after reading a book, and provides a variety of 
reports for teachers (Renaissance Learning, 2005b). Students receive points according to the length and the difficulty of the books they read, determined by a computeradministered readability program based on the Flesch-Kincaid readability index (Florida Center for Reading Research, 2004, p.1). Students may only gain points for books at their designated reading level. Library books are frequently color-coded with spine labels to allow easy identification of their AR level. Extrinsic rewards are usually offered to students as they gain points.

The AR program is gaining popularity internationally. By 2005, Renaissance Learning had offices in Canada, the U.K., and Australia in addition to the U.S. Renaissance Learning, the parent company of AR, reports that it is the world's most popular reading software and in 2005 is being used in 60,000 schools (Renaissance Learning, 2005b). The number of public and private K-12 schools in the U.S. $(119,235)$ lends some context to this number (U.S. Department of Education, National Center for Education Statistics, 2003b).

A great deal of research related to AR exists. Some researchers find AR to be an effective method for improving the reading of young people in grades K-12. For example, the Renaissance Learning web site, as of April 15, 2005, reports that 150 scientific studies support the effectiveness of Renaissance Learning products, including AR. Out of these 150 studies, 114 are identified as independent research (undefined). Other scholars find AR inhibits reading, particularly of those students who excel, and that it strictly circumscribes library collection development. For example, reference to some studies that do not support the effectiveness of the program can be found in the substantive reviews of the AR research by McQuillan (1997) and Krashen (2003, 2005). AR research includes 29 dissertations listed in Proquest's Digital Dissertations. An April 2005 online search limited to peer-reviewed journals of Education Index and Library Literature at Florida State University produced 22 articles.

Despite the number of studies, whether or not the AR program is effective and what that effectiveness means in the long run, are questions that still have no definitive answers. One response is that of the Florida Center for Reading Research, "its effectiveness. . .depends on its implementation" (2004, p. 1). The research reported in this paper does not address effectiveness of the AR program but rather focuses on the less examined areas of links between AR and information policy and reader motivation and reaction to $\mathrm{AR}$.

\section{Research Questions}

Different methods of data collection took place in the U.S. and the U.K. Therefore, the research questions will be addressed by the data set or sets that are more appropriate. The following research questions address three of the conference's six subthemes:

- How does national U.S. policy regarding reading achievement affect local school policy decisions regarding Accelerated Reader and what other factors affect local policy on AR? (Information Policy - U.S. focus).

- How is Accelerated Reader related to motivation, breadth of reading, and collection development? (Information Literacy - U.K. and U.S. focus). 
- How does the implementation of Accelerated Reader affect student reading practices? (Knowledge Management - U.K. focus).

\section{Methodology}

Quantitative and qualitative methodologies were employed to collect and analyze data for each of the research questions. All statistical tests were performed using the Statistical Package for the Social Sciences (SPSS). Qualitative analysis of the U.S. data was done with assistance of N6 Qualitative Analysis software.

Methodology in the U.S.

The U.S. schools in this study are among the poorest in the country. In the U.S. poverty in schools is usually measured by the number of children who receive free or reduced price lunch (FRL) ${ }^{2}$. The foundation from which the applicant data for this study is derived targets schools with $90-100 \%$ of their students eligible for FRL. In the 2003-2004 grant competition, 632 of the 893 schools that applied for library books had a student body that fell in this targeted poverty range. From these 632 applicant schools, a sample of 100 was selected for study using the random numbers generator of Excel. The 100 schools in this sample (mean=95.7, S.D. $=3.8$ ) did not differ significantly (Student's $\mathrm{t}=1.4, \mathrm{p}=0.153$ ) in percentage of FRL-eligible students from the underlying population of 632 (mean=95.1, S.D.=3.8). Therefore the results can be generalized to the applicant schools but not to the general U.S. population of schools. A school with only 10 students was dropped from the sample.

Schools were grouped by grade level into elementary schools (preK-5, ages 5-10) and secondary schools (6-12, ages 11-18). Schools also were grouped by state into four geographical regions as defined by the U.S. government: Northeast, Midwest, South, and West (U.S. Government, Fedstats, 2003), however there were too few in the Midwest $(n=9)$ to include in the analyses. Job titles were grouped into two categories (Library Staff and Other) depending on whether the respondent self-identified as a librarian ${ }^{3}$ or as someone with non-library responsibilities. Whether a school used Accelerated Reader was recorded.

School setting, student body ethnicity data, and the presence of migrant students were obtained from the Common Core of Data (U.S. Department of Education, National Center for Educational Statistics, 2003a) and the Private School Universe Survey (U.S. Department of Education, National Center for Educational Statistics, 2003c), both products of the National Center for Educational Statistics (NCES). The nine NCES categories for setting were collapsed into two: urban/suburban, and rural. In some schools, the student body consisted predominately (at least $85 \%$ ) of a single ethnic group. In others, no single group predominated; these were termed "multiethnic" schools.

T-tests, Mann-Whitney U tests, analyses of variance (ANOVA) and KruskalWallis $\mathrm{H}$ tests for differences in central tendencies among groups defined by the categorical variables described above were performed on the number of students, the number of books, the current year's book budget, the number of books per student, and the book budget dollars per student. Pearson and Spearman's correlations for assessing 
relationships between variables also were performed. Chi-square tests for relationships between variables and homogeneity of distributions were performed on the variables of region, setting, ethnicity, migrant students, Accelerated Reader use, grade level, and job title.

\section{Methodology in the U.K.}

Two schools in Scotland (one primary and one secondary) and one in England (primary) that had previously participated in Accelerated Reader research studies in the U.K. were identified via a literature search. ${ }^{4}$ These schools represent low (Scotland), $(n=53)$ middle (Scotland) $(n=40)$, and high (England) $(n=55)$ levels of implementation of AR. Levels of implementation were determined by Topping's criteria (1999; Topping \& Sanders, 2000; Topping \& Fisher, 2003) and include:

- intensity of the monitoring of student reading progress and intervention when needed,

- volume of AR reports,

- range of selections of books,

- level of access to computers for testing,

- degree of teacher training and support,

- variability in hardware and software configurations,

- level of teacher ability and interest in the program,

- nature and intensity of program use,

- limited and appropriate use of rewards, and

- time allocated for reading practice.

Data were collected in 2003. In the high level of implementation school, a primary school located in England, the AR program had been used for nine years and had evolved into the school's entire reading program. The Scottish schools are located in the same major city but in different areas. In the middle level implementation school, AR had been used by two teachers responsible for grade five and six for five years, and provided supplemental reading activities. In the low-level implementation school, a secondary school, AR was being used for only one year by Language Arts teachers in grades nine and ten who incorporate student performance into their term grade.

Observation, structured interviews with students and teachers, videotaped student focus groups, a student survey on self-reported reading, examination of AR artifacts, and administration of the Motivation for Reading Questionnaire (MRQ) (Wigfield \& Guthrie, 1997) were used to gather data. The MRQ measures the following dimensions of reading motivation: efficacy, challenge, curiosity, involvement, importance, recognition, grades, social, competition, compliance, and work avoidance. In addition to MRQ items, students were asked to respond in the survey to opinions of AR, gender, and age. AR reports were examined for total points to date (near the end of the school year) and total books read.

In order to obtain richer data about the instructional environments, focus group interviews with six groups of three students (two groups per school) were conducted. Teachers were asked to identify students who would be representative of the 
composition of their classroom in terms of reading ability and gender. The audio portion of the focus group videotapes was transcribed, and the contents consulted for clarification and expansion of the survey and MRQ data.

Differences in the means of total books read per week and of scores on reading motivation dimensions across groups defined by implementation level were tested using ANOVA. Differences in mean scores on reading motivation dimensions across groups defined by gender and by opinion of AR were tested using t-tests and ANOVA. Chi-square tests were used to examine the differences between genders and between implementation levels in students' opinions of AR. Spearman's correlation was performed to assess the relationship of total books read per week to number of AR points and to scores on reading motivation dimensions.

\section{Information Policy}

An examination of the Accelerated Reader program both in relation to national information policy and local information policy in the U.S. provides a response to the first research question.

\section{Information Policy in the U.S.}

In order to examine the relationship between the AR program and national policy in the U.S., one must understand the legislation that established the policy. The national reading policy for the U.S. was set with the passage of the No Child Left Behind Act of 2001 (NCLB), signed into law on January 8, 2002. The antecedents of this law reach back to the first version of the Elementary and Secondary Education Act of 1965, but the current version of this legislation brought with it sweeping changes that quickly permeated all fifty states. President George W. Bush singled out this educational reform legislation as a cornerstone of his administration. The stated purpose of the reform is to close the gap between low achieving children and their peers. Partially this is to be achieved by putting an emphasis on reading in grades $\mathrm{K}-3$ and through establishing Reading First programs in all fifty states. Another provision is to assure that all teachers are well qualified and using reading methodology found to be the most successful by scientific research. Accountability for these results is to come through establishment of individual state standards and by testing children grades three - eight annually in reading, math, and eventually in science against these standards. Test scores must be disaggregated by race or ethnicity to be sure that no particular racial or ethnic group of children are those who are left behind. "Minority and disadvantaged students are most at risk for falling behind" (U.S. Department of Education, 2004, p. 15). Student achievement must improve in each school each year, and the goal of NCLB is to assure that by the year 2013 all children read at their grade level. Both helps and penalties are spelled out for schools that fail to meet their goals.

This analysis requires understanding one addition report, i.e., that of the National Reading Panel (2000a). This panel of experts, set up during President Clinton's administration and charged with identifying the most important elements in a successful reading program, determined that they would consider only scientific research (National 
Reading Panel, 2000a). They defined scientific research as those studies appearing in peer-reviewed journals in which both experimental and control groups were used ${ }^{5}$. This decision eliminated the consideration of reading research that had been conducted using only qualitative methodologies, such as observation, interviews, focus groups, etc. The panel identified the following principles associated with reading success:

- alphabetics, including the issues of phonemic awareness instruction and phonics instruction,

- fluency, and

- comprehension, including vocabulary instruction.

The NRP endorsed these principles as the foundational elements in the successful teaching of reading (National Reading Panel, 2000b). The report of the NRP laid the groundwork for No Child Left Behind and the methodology advocated in Reading First programs throughout the U.S. It is not in the purview of this paper to examine whether or not NCLB is achieving its stated purposes but rather to note its impact on reading policy in U.S. schools.

\section{No Child Left Behind and School Library Media Centers}

In 2005 the American Association of School Librarians (AASL) issued a pamphlet, mailed to all principals in the U.S., the title of which is "Your School Library Media Program and No Child Left Behind." One of the headings in this pamphlet, "Helping Ensure All Students Pass State Tests," would have been considered somewhere between off-limits and anathema to librarians a decade or two ago. "School library media specialists," the text explains, "by designing and teaching information literacy units tied to the classroom curriculum, help all students learn not only to memorize information, but also to use it in meaningful and memorable ways. Which, of course, leads to higher test scores" (American Association of School Librarians, 2004).

The foundation applications were examined in order to determine to what extent building level media specialists consider the implications of NCLB spelled out by the AASL as important to their own collection development. Seven percent of the applicants make specific mention of NCLB. However, numerous others demonstrate its probable influence through the mention of state standards and achievement test scores in relation to library collections and reading. For example, several applicants articulate the following type of need: "The books purchased will support our state standards and the curriculum in a wide range of reading levels." One applicant made this direct link to NCLB, "With the requirements of the No Child Left Behind legislation, it is vital that we provide an abundance of reading materials. . . that produce successful readers." This same applicant noted that his/her school has applied for a Reading First grant. Another applicant states that "as we work toward our No Child Left Behind goals, a viable library is a necessity." The AASL pamphlet and the comments from the foundation applicants leave no doubt that NCLB is a component of national information policy nor that it has an impact on information policy in local school libraries. 


\section{No Child Left Behind and Accelerated Reader}

Nor is the relationship between NCLB and AR left to the imagination. On the Renaissance Learning web page titled "Better Data Means Better Learning" a small graphic of a red, white, and blue American flag announces an association between AR and NCLB (Renaissance Learning, 2005a). When one clicks on the flag, another page appears with the title "Renaissance Solutions Meet the Requirements of No Child Left Behind" (Renaissance Learning, 2005c). A link from this second page reveals a chart of types of Renaissance research, ${ }^{5}$ with a note that "the research supporting Renaissance meets the requirements of scientific research as outlined in the No Child Left Behind Act of 2001" (Renaissance Learning, 2005c). However, only 40 of 150 studies listed are experimental, and a list of the reading research studies also linked off this page reveals that the majority are not published in peer-reviewed journals (Renaissance Learning, 2005c). Two other links lead to a paper, "How Scientific Research Supports the School Renaissance School Improvement Process" and to an elaborate diagram called a Research Pyramid Flow Chart (Renaissance Learning, 2005c). The title on this complex graphic reads "Renaissance Solutions Fulfill Assessment Requirement of No Child Left Behind." Here, various levels of the pyramid are correlated with requirements of NCLB and with Renaissance Learning products, including AR. The alignment of AR with individual state standards is also spelled out (Renaissance Learning, 2005d).

\section{No Child Left Behind, School Media Centers, and Accelerated Reader}

It has been established that seven percent of the applicant schools related NCLB principles to their need for library books and that others made requests that would meet the NCLB requirements without naming it explicitly. An additional $27 \%$ of the schools in the study population as for funds to support Accelerated Reader, citing its relationship to the requirements of $\mathrm{NCLB}$, again without referring to the legislation by name ${ }^{6}$. For example, one applicant says "Since the introduction of AR, library circulation improved by $50 \%$ and test scores are rising steadily." Another applicant states "Since implementing Accelerated Reader a number of years ago we have seen our students' reading scores on standardized tests grow steadily." And a third applicant stated, "Our students' reading scores [on standardized tests] have improved with the use of this program." And another, "In 1995-1996, xxxx was deemed a Low Performing school by TEA [Texas Education Association] based on low Reading and Math scores. With a strong emphasis on Reading using the Accelerated Reader program, our students now perform among top schools in the state."

\section{Local School Demographics and Accelerated Reader}

A number of demographic variables were analyzed for correlations with the adoption of Accelerated Reader. Results showed that schools mentioning the use of AR have student bodies less ethnically diverse than schools that do not (Chi square $=3.9,1$ d.f., $\mathrm{p}<0.05$ ). These schools have student bodies of at least $85 \%$ of Asian, African American or Hispanic students (none of the study population schools had predominately white populations). Also, schools that mention the use of AR had 2003-2004 book budgets that are significantly lower than those of schools that did not mention AR (Mann- 
Whitney $U=606.0, p<0.05)$. A similar finding appeared in a previous analysis of data from 2002-2003 applications to the same private foundation in which a sample was drawn from schools reporting $25 \%$ or less free or reduced lunch and another from schools reporting $75 \%$ or above (the poverty target group in that round of applications). It was found that "use of the AR Program was mentioned significantly more times (Chisquare $=8.86$, d.f. $=1, \mathrm{p}<0.01$ ) by schools with the poorest students than by those with richer ones" (Dresang \& Kotrla, p. 16). Each of these findings indicate that poorer schools with the most need and the most homogeneous minority populations are more likely to choose the AR program when given an opportunity to obtain funds. This suggests that the AR program is seen as a way to meet the national information policy requirements on a local level, particularly by those schools with a high percentage of the populations targeted by the NCLB legislation.

Other variables were tested in relation to the choice of AR, but no significant relationships were found between urban versus rural settings, the level of instruction (elementary or secondary), the presence or absence of migrant students, the number of students, the number of books, or whether a certified librarian or someone else oversees the library.

\section{Information Literacy}

Information literacy issues related to motivation to read, student attitudes, and breadth of reading from the perspective of students in Accelerated Reader programs provide a framework to address the second research question using the case study data from the U.K. schools. The data collected in the U.S. schools requesting AR funds provide some additional insights into how their librarians envision collection development in relation to AR and information literacy.

\section{Motivation}

Many of the motivational aspects of AR have not been thoroughly examined even though "getting students excited about books" is also widely promoted by the manufacturer of the program (Renaissance Learning, 2005b). In the U.S., tangible (extrinsic) rewards as motivational tools are often associated with the use of the AR program and this practice has been criticized (Kohn, 1993; Carter, 1996) as actually leading to diminished motivation in reading. Renaissance Learning (1997) maintains that

the use of extrinsic rewards is not an essential part of Accelerated

Readers use. AR provides learning information which teachers can use in a variety of ways, including reading incentive programs. Such programs, while not the only way to motivate student reading, can also serve as important, tangible feedback that helps students discover an intrinsic love of reading and learning within themselves. (p.3)

One of the reasons for seeking out schools in the U.K. was to study reading motivation in another cultural context - the absence of competition and related prizes because is has been maintained that extrinsic rewards for reading would generally be considered inappropriate, if not unacceptable (Topping, 1999). But unexpectedly, teachers in the Scottish schools (low and mid-level implementation) were eager to show 
this American researcher how they had implemented the AR program "American-style" with a large array of prizes ordered from the Renaissance Learning catalog that included school supplies and small toys. The mid-level implementation school also displayed students' names who had reached $100 \%$ of their AR goal for the term on a bulletin board in a prominent area of the hallway as did the English school (high implementation) whose only other tangible reward was having the principal affix a sticker on a student's shirt in assembly when he/she had met an AR goal. In each of the U.K. schools the one distinct culturally related aspect of the implementation of AR was that there was no competition between students or classrooms of students to accumulate points. Students, with the help of their teachers and the diagnostic portion of the AR program, set individual goals and were rewarded by performance feedback inherent in the program and teacher praise, which have been shown to be highly motivating (Cameron \& Pierce, 1994).

Another finding was that some students were motivated to read a large number of non-AR books, despite the lack of rewards for this reading, and reportedly did so because AR quizzes were not available for books they were interested in reading. These books fell into two distinct categories - higher-level adult fiction and newly published books. Teachers at the high-implementation school did demonstrate an effort to read these types of books and construct their own AR quizzes, an option of the software.

The number of books a student reads might be assumed to have some relationship to his or her motivation to read. In turn this motivation might be related to something called motivational style. Through administration of the MRQ to students in England and Scotland, an attempt was made to distinguish among motivational styles and number of AR books read. However, most of the motivational styles were significantly correlated with the number of books read: efficacy, challenge, curiosity, aesthetic enjoyment, importance, recognition, social, intrinsic composite and extrinsic composite (Table 1) so motivational style is not helpful as a distinguishing feature in determining impact on information literacy, except when gender is taken into account as is explained later.

Table 1. Motivational Styles \& Volume Of Reading -Spearman's Correlation Coefficient

\begin{tabular}{|l|c|c|}
\hline \multicolumn{1}{|c|}{ Motivational style } & Correlation coefficient & P \\
\hline Efficacy & 0.18 & $\mathrm{p}<0.05$ \\
\hline Challenge & 0.18 & $\mathrm{p}<0.05$ \\
\hline Curiosity & 0.25 & $\mathrm{p}<0.01$ \\
\hline Aesthetic enjoyment & 0.22 & $\mathrm{p}<0.01$ \\
\hline Importance & 0.24 & $\mathrm{p}<0.01$ \\
\hline Recognition & 0.23 & $\mathrm{p}<0.01$ \\
\hline Social & 0.17 & $\mathrm{p}<0.05$ \\
\hline Intrinsic Composite & 0.31 & $\mathrm{p}<0.01$ \\
\hline Extrinsic Composite & 0.19 & $\mathrm{p}<0.05$ \\
\hline
\end{tabular}


An attempt was made to determine if students who had differing opinions of AR were motivated differently. The majority of students (66\%) like AR, 21\% don't like it and $13 \%$ have no opinion. No significant differences were found in motivational style among students with different opinions of AR (ANOVA: $F=1.977, p>0.05$ ). Students were also given the opportunity to respond to two open-ended questions in the survey: What do you like about AR? What don't you like about AR? Broad categories of responses can be found in Table 2. The most popular response was related to computer/software/test format for both likes (37\%) and dislikes (30\%). More specific responses in this category were that students liked using the computer, taking tests, and the question format of AR. Dislikes included question difficulty, seeing mistakes, and quizzes being boring. Twenty-five percent of students disliked the selection of books associated with AR, an aspect of implementation that is frequently criticized (Carter, 1996). Related to competition/achievement, $18 \%$ of students who enjoy this mentioned prizes and points, and the $14 \%$ who disliked it noted scores being posted and program pressure, a finding similar to Eccles, Wigfield, \& Schiefele (1998).

Table 2. Student Likes and Dislikes Regarding AR

\begin{tabular}{lllll}
\hline & Like & \% & Dislike & \% \\
Reading & 48 & $33 \%$ & 10 & $8 \%$ \\
Selection of books & 14 & $10 \%$ & 32 & $25 \%$ \\
Computer/software/test format & 55 & $37 \%$ & 39 & $30 \%$ \\
Competition/achievement & 26 & $18 \%$ & 18 & $14 \%$ \\
Nothing & 4 & $3 \%$ & 30 & $23 \%$ \\
Total & 147 & $100 \%$ & 129 & $100 \%$ \\
\hline
\end{tabular}

A significant gender difference existed in opinion of AR: a greater proportion of females like AR (Chi square=6.44, 2 d.f., $\mathrm{p}<0.05$ ). This supports previous U.K. research that found more positive attitudes towards AR in girls (Topping \& Fisher, 2003) and that boys have shown a decline in reading for pleasure since the government's emphasis on improving literacy (Harlen \& Deakin, 2002). Teachers in this study were shown AR reports and asked which students AR helped and which students had difficulty with AR. In all instances, teachers pointed out boy students as feeling pressured by AR. Topping (1999) notes that delayed readers (who are most often boys) might not want to be seen reading low readability books, and they may therefore choose books that are too difficult for them. This would also lead to unfavorable opinions of the program.

Boys and girls differed in the social and competition motivational scales on the MRQ with boys scoring significantly higher in competition, $\mathrm{t}(146)=-2.852, \mathrm{p}=.01$ and girls in social $\mathrm{t}(146)=2.08, \mathrm{p}=.05$. Scoring high on the social scale meant the girls responded more positively to statements about reading with friends and family and 
discussing books. Scoring high on the competition scale meant the boys responded more positively to statements about being recognized and attaining good grades. It could be suggested that one of the reasons girls like AR is that it provides a context for the social nature of reading, which they enjoy. It might also be suggested that boys enjoy the competition aspect of AR, which includes recognition when they do well.

\section{Breadth of Reading}

If students are motivated to read, it is probable that they will read more books. This study found no correlation between the number of books read and the number of AR points (Spearman's correlation coefficient -0.075, $\mathrm{p}>0.05$ ). One might expect there to be a direct correlation with the number of books read and AR points as the more books that are read, the more points can be accumulated. The reasons for there not being a correlation could be (a) a large number of books with low point levels were read (as was observed in the mid-implementation school), (b) books being read that were not AR books (as was the case in the school where students read books from outside the classroom), (c) a lower number of books with higher point values being read (more difficult books), and (d) failing AR tests and not receiving points for books that were read.

\section{Collection Development}

In the schools in the U.S. study that have adopted the AR reading program, it has had a substantial impact on collection development. Librarians in this study using the AR program have a great deal of confidence in its efficacy in promoting information literacy. It is to be expected, of course, that most of these applicants are enthusiastic about the AR program since they are requesting funds to enhance its use. "Since the advent of the AR program, the students are seen reading at every possible moment during the school day and after school. The students are also talking to their peers about books and recommending some of the books they liked. Prior to AR many. . . books . . would be returned not read." And another librarian states that "with a strong emphasis on Reading using the Accelerated Reading program, our students now perform among top schools in our city."

Some librarians took care to note that they do not rely solely on AR in choice of books. In one grade 7-12 school with 99\% Native American youth, the school staff proposed using the entire book budget for AR books. They noted that "our AR collection currently consists of 1764 books, 1505 of which are below the sixth grade level." So their purpose was to purchase books that fall into the seventh - twelfth grade range. "Accelerated Reader," they write," is one tool that we have identified for our reading program that has proved effective." They went on to say that their student's standardized tests scores have risen so much since starting AR that they no longer need the number of below-reading-level books that they had once emphasized. However, although they proposed using the AR catalog to locate potential purchases, they noted that they planned to check with other recommended lists to guide their final selection. The more typical applicant, however, focused directly on the purchase of AR books with particular emphasis on obtaining enough quizzes to match books to satisfy student demand. 
"Funding would allow for computer tests to have the needed print resource available through the media program. Student frustration of not having matching resources would be eliminated." Another applicant who planned to use all the funds for AR books maintains that "the AR books comprise approximately $98 \%$ of all books check out by the students." Other applicants acknowledged that the reason they needed the grant funds was that their book budget has gone to purchase AR books and quizzes, leaving little for other materials. Still the lure of AR is strong. One applicant noted the dire need for non-fiction and a plan to evaluation the entire non-fiction collection using Evaluating the School Library Media Center (Everhart, 1998). But, the applicant says, with an almost audible sigh, that although they will value the evaluation, "we will ultimately seek AR titles."

\section{Knowledge Management}

Knowledge management decisions concerning the implementation of the Accelerated Reader program and how this might impact students relate to the third research question.

\section{Implementation}

Over 30 reports can be generated with $\mathrm{AR}$ to assist teachers and administrators as they serve as knowledge managers of reading. However, the average number of reports employed by all teachers in the three schools was two. Even though there is great potential to use data for decision-making, it was not observed in the study schools. If school personnel implement the AR program effectively, they should be able to realize its potentials - one of which is getting students to read more books. There was a significant difference in the number of books read among the levels of implementation (ANOVA: $\mathrm{F}=28.68, \mathrm{p}<0.01$ ) in the U.K. schools. However, it was the school with the medium level of implementation that reported the highest mean volume of reading per week per student. Although this sounds counter-intuitive, observation and an AR report listing the most popular books revealed these to be 12-20 page picture books that ten year-old students could finish reading in a matter of minutes. The teacher who administered AR produced this report at the request of this researcher, and was quire embarrassed at the results, having done it for the first time. He felt it was important to have a large number of easy books for students to gain confidence in their abilities, but admitted lack of guidance for students in their reading choices. Students in this low socio-economic school also were interested in accumulating AR points for prizes and having their name displayed on a bulletin board in the hallway, which has been shown to be highly motivating (Vollands, Topping, \& Evans, 1999) and confirmed by students in the focus groups.

Levels of implementation were related to the following types of motivation at significant levels: aesthetic enjoyment $(\mathrm{F}=4.07, \mathrm{p}<0.05)$, recognition $(\mathrm{F}=4.25, \mathrm{p}<0.05)$, and social $(\mathrm{F}=5.22, \mathrm{p}<0.01)$, which were all higher for both the high and middle-levels of implementation schools than the low-level of implementation school. It is unknown why there was a relationship, however a major difference might be that the students in the low 
implementation school were of a different age range (secondary school) than the other two schools and interest in reading tapers off as children get older.

There was no relationship between students' opinions of AR and level of implementation (Chi-square $=1.86,4$ d.f., $\mathrm{p}>0.05$ ). Opinions of AR were very similar regardless of how it was implemented. In the focus group interviews, teachers noted that students liked being responsible for their own learning and being evaluated by a computer that was deemed impartial. AR is also a novelty in the U.K. - very few schools have it and these students may feel they have something special in their classrooms.

\section{Conclusions}

Conclusions drawn from the U.S. and the U.K. data sets in this cross-cultural, cross-methodological study provide the impetus for further research in both settings. The U.S. data support the conclusion that there is a strong relationship between national information policy regarding reading achievement as embodied in the No Child Left Behind Act of 2001 and some local policy decisions to use Accelerated Reader in U.S. schools with the poorest students. Adopting AR directly affects expectations regarding literacy and collection development practices in these school libraries. Minority and disadvantaged students are most likely to fall behind in school, and schools in this study with the most homogeneous minority populations and lowest book budgets are also most likely to adopt the AR program ${ }^{7}$. These U.S. conclusions might prompt further comparative research in Scotland (with a low key approach to standardized testing) and England (with a high stakes approach more similar to the U.S.) to determine whether these national information policies affect adoption of the Accelerated Reader program in each of these cultures and whether adoption of the program varies according to socioeconomic level.

The U.K. data support the information literacy conclusion that motivational style interacts with gender in relation to the competitive and social aspects of the AR program. One might conclude that AR prizes are more effective with boys, but that boys are equally motivated by praise and recognition, and that girls are motivated more by discussing books and reading with others and generally like the AR program better. In the area of knowledge management, the data lead to the conclusions that teachers tend to ignore the many possible AR reports, thus neglecting useful reading guidance, and that level of program implementation (high, medium or low) does not correlate with breadth of reading. These conclusions prompt seeking comparable U.S. schools and probing, along with knowledge management issues, how students' opinion toward the AR extrinsic rewards and the program in general might differ between boys and girls or whether this is more of a culturally specific finding given the less competitive nature of AR program implementation in the U.K.

The results of this study cannot be generalized beyond the populations studied. However, an overall conclusion is that the Accelerated Reader program has the potential to have a significant impact on schools and school libraries and their missions related to information policy, information literacy, and knowledge management and that 
it is important for research in this area to be widely discussed and disseminated and for its implications for implementation to be carefully examined.

\section{Explanatory Endnotes}

${ }^{1}$ Two of the researchers serve as consultants to this Foundation and have full access to the applicants' data and permission to use it. However, for privacy purposes neither the applicants nor the Foundation will be named or in any other way identified in this paper.

${ }^{2}$ Children from families with incomes at or below 130 percent of the current U.S. poverty level for a family of the size of theirs are eligible for free meals and those in families with incomes from 130-185 percent of the current poverty level are eligible for reduced price lunches.

${ }^{3}$ The terms school librarian and media specialist as well as school library or media center will be used interchangeably and across cultures in this study.

4 The principal investigator of those studies, Keith Topping from the University of Dundee, Scotland, agreed to host this researcher and made contacts with schools for site visits. These schools had been involved in previous studies with Topping and relevant permissions had already been secured.

${ }^{5}$ This chart refers to the 150 studies previously mentioned. The Renaissance Learning web site is permeated with references to scientifically based research (Renaissance Learning, 2005b,

${ }^{6}$ The reader should be cautioned not to compare this to previously cited use statistics as other schools in this sample may use AR but not focus on it as the most important need for the collection development grant funds.

${ }^{7}$ This data analysis describes a relationship between the adoption of AR and the poorest U.S. schools. It does not evaluate or address the efficacy or effectiveness of this practice or the assumptions behind it. 


\section{References}

American Association of School Librarians. (2004). Your school library media program and No Child Left Behind. Chicago: American Library Association.

Cameron, J., \& Pierce, D. W. (1994). Reinforcement, reward, and intrinsic motivation: A meta-analysis. Review of Educational Research, 64, 363-423.

Carter, B. (1996). Hold the applause! Do Accelerated Reader \& Electronic Bookshelf send the right message? School Library Journal, 42(10), 22-25.

Dresang, E., \& Kotrla, B. M. (2003). Breaking barriers with student-centred teaching and learning using library books in the United States' poorest schools. In S. Zinn, G. Hart, \& E. Howe (Eds.), Selected papers from the 32nd annual conference and the international forum on research in school librarianship, Durban South Africa, 7-11 July 2003 (pp. 54-70).

Seattle, WA: International Association of School Librarianship.

Eccles, J. S., Wigfield, A., \& Schiefele, U. (1998). Motivation to succeed. In W. Damon \& N. Eisenberg (Eds.), Handbook of child psychology: Socialization, personality, and social development (pp. 601-642). New York: Wiley.

Everhart, N. (1998). Evaluating the school library media center: Analysis techniques and research practices. Englewood, CO: Libraries Unlimited, Inc.

Florida Center for Reading Research. (2004). Accelerated Reader. Retrieved April 15, 2005, from www.fcrr.org/FCRRReports/PDF/Accelerated_Reader.pdf

Harlen, W., \& Deakin, R. (2002). A systematic review of the impact of summative assessment and tests on students' motivation for learning. London: EPPI-Centre, Institute of Education. 
Kohn, A. (1993). Punished by rewards: The trouble with gold stars, incentive plans, A's, praise, and other bribes. Boston: Houghton Mifflin.

Krashen, S. D. (2003). The (lack of) experimental evidence supporting the use of Accelerated Reader. Journal of Children's Literature, 29(2), 16-30.

Krashen, S. D. (2005). Accelerated Reader: Evidence still lacking. Knowledge Quest, 33(3), 48-49.

McQuillan, J. (1997). The effects of incentives on reading. Reading Research and Instruction, 36(2), 111125.

National Reading Panel. (2000a). Teaching children to read; Summary report. Retrieved April 15, 2005, from http://www.nationalreadingpanel.org/Publications/summary.htm

National Reading Panel. (2000b). Teaching children to read; Findings and determinations of the National Reading Panel by topic areas. Retrieved April 15, 2005, from http://www.nichd.nih.gov/publications/nrp/findings.htm

No Child Left Behind Act of 2001.Pub. L. No. 101-336 (2002). Retrieved April 15, 2005, from http://www.ed.gov/policy/elsec/leg/esea02/index.html

Renaissance Learning. (1997). Toward a balanced approach to reading motivation: Resolving the intrinsic - extrinsic rewards debate. Madison, WI: The Institution for Academic Excellence.

Renaissance Learning (2005a). Better data means better teaching and learning. Retrieved April 15, 2005, from http://www.renlearn.com/default.htm

Renaissance Learning. (2005b). Build a lifelong love of reading and learning! Retrieved April 13, 2005, from http://www.renlearn.com/ar/overview/default.htm

Renaissance Learning. (2005c). Renaissance solutions meet the requirements of No Child Left Behind. 
Retrieved April 15, 2005, from http://www.renlearn.com/nclb.htm.

Renaissance Learning. (2005d). State Standard Alignment. Retrieved April 15, 2005, from

http://www.renlearn.com/fundingcenter/statestandardalignments/.

Topping, K. J. (1999). Formative assessment of comprehension by computer: Advantages and disadvantages of the Accelerated Reader software, Reading Online. Retrieved April 15, 2005, from http://www.readingonline.org/critical/topping/

Topping, K. J., \& Fisher, A. M. (2003). Computerized formative assessment of reading comprehension: Field trials in the UK. Journal of Research in Reading, 26(3), 267-279.

Topping, K. J., \& Sanders, W. L. (2000). Teacher effectiveness and computer assessment of reading: Relating value-added and learning information systems data. School Effectiveness and School Improvement, 11(3), 305-337.

U.S. Department of Education. (2004). A guide to education and No Child Left Behind. Retrieved April 15, 2005, from ww.ed.gov/nclb/overview/intro/guide/guide.html

U.S. Department of Education. National Center for Educational Statistics. (2003a). Common core of data: Information on public schools and school districts in the United States (2001-2002). Retrieved April 15, 2005, from http://nces.ed.gov/ccd/aboutCCD.asp

U.S. Department of Education. National Center for Educational Statistics. (2003b). Educational institutions. Retrieved April 15, 2005, from http://nces.ed.gov/fastfacts/display.asp?id=84

U.S. Department of Education. National Center for Educational Statistics. (2003c). Private school universe survey (2001-2002).

U.S. Government. Fedstats. (2004). Mapstats. Retrieved April 15, 2005, from http://www.fedstats.gov/qf/ 
Vollands, S. R., Topping, K. J., \& Evans, R. M. (1999). Computerized self-assessment of reading comprehension with Accelerated Reader: Action research. Reading and Writing Quarterly, 15(3), 197-211.

Wigfield, A., \& Guthrie, J. T. (1997). Relations of children's motivation for reading to the amount and breadth of their reading. Journal of Educational Psychology, 89, 420-432.

\section{Author Notes}

Dr. Nancy Everhart, Associate Professor, College of Information, Florida State University, (U.S.A.), joined the faculty as Director of the School Media Program after ten years at St. John's University, New York City. She is the author of Evaluating the School Library Media Center and Controversial Issues in School Librarianship. An active member of the American Association of School Librarians, she currently serves as associate editor of School Library Media Research and research editor of Knowledge Quest. Her research focuses on the impact of technology on the role of the school library media specialist and has won several national awards.

Dr. Eliza T. Dresang, Eliza Atkins Gleason Professor, College of Information, Florida State University (U.S.A.) was Director of Library and Technology Services in the Madison (WI) School District from 1980 - 1996. Much of her academic research, publishing, and teaching focuses on information-seeking behavior of youth and their resources in a digital environment. She is internationally recognized for her scholarship, including her award-winning book Radical Change: Books for Youth in a Digital Age and her co-authored book School Censorship in the $21^{\text {st }}$ Century: A Guide for Teachers and School Media Specialists. 
Dr. M. Bowie Kotrla is the Director of Information Services for the College of Information, Florida State University (U.S.A.). She earned her doctorate in Biology and conducted research in biometrics and parasitic disease. After earning a second Master's degree in Information Studies, she joined the faculty at the College where she teaches research methods and database management. Her research interests concern issues of access to information by children and young adults. She serves on the Intellectual Freedom Committee of the American Library Association. 
Reproduced with permission of the copyright owner. Further reproduction prohibited without permission. 